\title{
CERTIFICAÇÕES COMO ESTRATÉGIA DE UPGRADING NA CADEIA DE VALOR DO LEITE EM PALMAS/TO
}

Certifications as upgrading strategy in the milk value chain in Palmas/TO

\section{Desafios}

Certificaciones como estratégia de actualización en la cadena de valor de leche en Palmas/TO
Artigo Original Original Article Artículo Original

\section{Alessandra Polastrini ${ }^{1}$, Manoel Xavier Pedroza Filho ${ }^{2}$ \\ ${ }^{1}$ Programa de Pós-Graduação em Desenvolvimento Regional, Universidade Federal do Tocantins, Palmas, Brasil. \\ ${ }^{2}$ Embrapa Pesca e Aquicultura/Programa de Pós-Graduação em Desenvolvimento Regional, Embrapa Pesca e Aquicultura/Universidade Federal do Tocantins, Palmas, Brasil.}

*Correspondência:Av. NS 15 ALC NO 14, Prédio do PPGDR, Universidade Federal do Tocantins, Palmas,

Tocantins, Brasil.CEP:77.020-210.E-mail pgdra@uft.edu.br.

Artigo recebido em 17/09/2020 aprovado em 27/01/2021 publicado em 28/06/2021.

\section{RESUMO}

A cadeia leiteira em Palmas, Tocantins, é relevante socialmente e possui lacunas que pedem intervenção, como a alta informalidade. O propósito deste estudo foi elencar certificações que promovam a ascensão de produtores de leite para melhores posições dentro da cadeia global de valor do leite no município de Palmas. O estudo consistiu em entrevistas a 58 atores da cadeia leiteira de Palmas em outubro de 2019. A estrutura teórica adotada foi a cadeia global de valor, focando na dimensão upgrading, que considera as diferentes possibilidades de melhoria da posição dos atores na cadeia de valor. Verificou-se uma alta informalidade entre os produtores entrevistados (77,5\%), sendo que apenas 10\% comercializam formalmente a produção láctea e 5\% possuem Selo Artesanal. Foi verificado interesse na formalização, embora a assimetria de informação e poder sejam barreiras significativas. Certificações como S.I.M., S.I.E., Selo Artesanal, Produto Orgânico e leite A2 constituem em caminhos para upgrading, agregando maior valor aos produtos e segurança financeira ao produtor. A conquista de certificações depende de aspectos que envolvem não apenas os atores da cadeia mas também o Poder Público.

Palavras-chave: Cadeia do leite. Informalidade. Certificação.

\section{ABSTRACT}

The dairy chain in Palmas, Tocantins, is socially relevant and has gaps that call for intervention, such as high informality. The purpose of this study was to list certifications that promote the rise of milk producers to better positions within the global milk value chain in the municipality of Palmas. The study consisted of interviews with 58 actors in the Palmas dairy chain on October 2019. The theoretical framework adopted was the global value chain, focusing on the upgrading dimension, which considers the different possibilities for improving the position of the actors in the value chain. There was a high level of informality among the interviewed producers (77,5\%), with only $10 \%$ formally selling dairy products and 5\% having an Artisanal Seal. Interest in formalization was noted, although information and power asymmetry are significant barriers. Certifications such as S.I.M., S.I.E., Artisanal Seal, Organic Product and A2 milk constitute paths for upgrading, adding greater value to products and financial security for the producer. The achievement of certifications depends on aspects that involve not only the actors in the chain but also and the government.

Keywords: Milk chain. Informality. Certification. 


\section{RESUMEN}

La cadena láctea de Palmas, Tocantins, es socialmente relevante y tiene brechas que requieren intervención, como la alta informalidad. El propósito de este estudio fue enumerar las certificaciones que promueven el ascenso de los productores de leche a mejores posiciones dentro de la cadena de valor global de la leche en el municipio de Palmas. El estudio consistió en entrevistas a 58 actores de la cadena lechera de Palmas en octubre de 2019. El marco teórico adoptado fue la cadena de valor global, con foco en la dimensión de mejora, que considera las diferestes posibilidades de mejorar la posición de los actores en la cadena de valor. Hubo alta informalidad entre los productores entrevistados (77,5\%), con solo el $10 \%$ vendiendo productos lácteos formalmente y el $5 \%$ con Sello Artesanal. Se notó interés en la formalización, aunque la información y la asimetría de poder son barreras importantes. Certificaciones como S.I.M., S.I.E., Sello Artesanal, Producto Orgánico y Leche A2 constituyen caminos de mejora, agregando mayor valor a los productos y seguridad financiera para el productor. La consecución de certificaciones depende de aspectos que involucran no solo a los actores de la cadena sino también al gobierno.

Descriptores: Cadena de leche. Informalidad. Certificación.

\section{INTRODUÇÃO}

A cadeia do leite se destaca por ser uma das mais importantes para o desenvolvimento regional (ACETO et al., 2017; FAO, 2019). O leite é uma das commodities mais significativas, tanto em âmbito econômico como social, proporcionando melhorias na qualidade de vida dos atores envolvidos direta e indiretamente no setor (OTTE e FELIS-ROTA, 2018). No Brasil a atividade leiteira é praticada em todas as regiões (SILVA et al., 2017). O país é o terceiro maior produtor mundial, produzindo 30 bilhões de litros (SIDRA, 2020). O estado do Tocantins é o terceiro maior produtor da região norte, registrando produção de 237 milhões de litros em 2017. Aproximadamente $75 \%$ dos estabelecimentos produtores são da agricultura familiar (SIDRA, 2020). Os municípios que mais se destacam na atividade são Araguatins, Pequizeiro, Bernardo Sayão, Araguaína e Colmeia. Estes foram essenciais para alavancar a produção estadual em 250\% desde a sua criação em 1988 (SIDRA, 2020).

A capital, Palmas, possui 303 estabelecimentos produtores de leite, ordenhou 1.680 vacas que produziram, em 2017, 2,2 milhões de litros de leite (SIDRA, 2020). Apesar de não estar entre os maiores produtores, Palmas apresentou um acréscimo de $300 \%$ na produção entre 1995 e 2017 (SIDRA, 2020).
Polastrini et al. (2020) identificaram os gargalos da cadeia leiteira de Palmas. De acordo com os autores os principais gargalos estão relacionados ao manejo dos animais (especialmente a nutrição), alto custo de produção (insumos e serviços), logística, assimetria de poder entre os atores da cadeia, falhas na transferência de tecnologia dentro da cadeia, falta de assistência técnica, informalidade e cultura dos atores da cadeia. Polastrini et al. (2020) ressaltaram que houve uma evolução expressiva na cadeia desde a criação do município e a medida que esses gargalos forem trabalhos e estudos é possível uma maior expansão da atividade.

Além disso, concentra o maior mercado consumidor do estado, que apresenta também a maior renda per capita, movimentando o comércio municipal. Neste sentido, o presente trabalho se justifica por se tratar de uma cadeia relevante nos aspectos econômico, social e cultural, balizando o almejado desenvolvimento regional.

Apesar disso, a demanda municipal por lácteos é maior que a oferta. Como agravante, a produção palmense é predominantemente informal, tornando a atividade insegura e instável economicamente para os produtores (POLASTRINI et al., 2020). São escassos os estudos sobre a cadeia do leite em Palmas e mesmo no estado de Tocantins. Em vista da informalidade e os problemas decorrentes dessa condição produtiva e 
comercial, também não há pesquisas publicadas que mencionem caminhos plausíveis para amenizar ou sanar o problema.

Visando preencher essa lacuna, neste estudo houve o foco na dimensão upgrading pois esta “concentra-se nas estratégias usadas por países, regiões e outras partes econômicas interessadas para manter ou melhorar posições na economia" (GEREFFI e FERNANDEZ-STARK, 2016, tradução nossa). A certificação é um modo importante para o upgrading, uma vez que pode implicar em uma maior agregação de valor aos produtos (PEDROZA FILHO et al., 2015).

Neste sentido, o principal questionamento que norteou a pesquisa foi o seguinte: Quais certificações podem promover o upgrading ao produtor de leite? Para tanto, o objetivo da pesquisa foi elencar certificações que promovam a ascensão de produtores de leite para melhores posições dentro da cadeia global de valor do leite no município de Palmas.

Este artigo está estruturado em cinco seções: esta introdução ao assunto pesquisado, seguida pela revisão bibliográfica. Na terceira seção é apresentada a metodologia adotada para se alcançar o objetivo do estudo; seguem-se os resultados e discussão e, por fim e não menos importante, as considerações finais que sintetizam o estudo, traçando os caminhos potenciais para a problemática abordada.

\section{O UPGRADING EM CADEIAS GLOBAIS DE VALOR}

Atualmente verifica-se um elevado nível de fragmentação das etapas produtivas e a globalização da produção e comércio. Houve aumento expressivo das interdependências econômicas entre os países e da produção de insumos intermediários. O resultado é uma maior inserção de países em desenvolvimento no mercado global sem a necessidade da aquisição de competências em todas as etapas produtivas, como ocorreu em países desenvolvidos (GEREFFI e FERNANDEZ-STARK, 2016).

Esse fenômeno foi batizado por Gary Gereffi, de cadeia global de valor (CGV) e é definido como "toda a gama de atividades que as empresas e os trabalhadores realizam para trazer um produto desde a sua concepção até o uso final e além" (GEREFFI e FERNANDEZ-STARK, 2011, p.4, tradução nossa). Para analisar os elementos de uma cadeia, seis dimensões são consideradas: insumo-produto, escopo geográfico e governança, que estruturam a análise a nível global ou Top-Down; upgrading, contexto sócioinstitucional e stakeholders, que fundamentam a análise a nível local ou Bottom-Up (GEREFFI e FERNANDEZ-STARK, 2016).

Todavia, esse mundo moderno e globalizado desenha desafios gritantes, como o crescimento populacional, alta urbanização, insegurança alimentar, degradação ambiental e pandemias, como a atual Covid-19. As cadeias agroalimentares, especialmente, são notáveis por minimizarem o êxodo rural, sustentar a produção de alimentos e garantirem a segurança alimentar e gerarem emprego e renda.

O framework de CGV tem o potencial de traçar trajetórias que estabeleçam novos padrões de produção e comercialização, tornando as cadeias cada vez mais sustentáveis, constituindo-se em um caminho para o melhoramento da cadeia de valor, o denominado upgrading. Lowe e Gereffi (2009) constataram que a empresas e atores a jusante da cadeia tem substancial poder de "moldar" os sistemas produtivos, tornando-os ecologicamente corretos.

Essa dimensão de análise é a mais importante a nível Bottom-Up, ou seja, de baixo para cima, respondendo à seguinte questão: como essa cadeia local ou regional pode evoluir para além dos seus atuais limites, 
capturando benefícios sociais, econômicos, ambientais entre outros. O upgrading permite avaliar como as cadeias e empresas podem evoluir em suas posições na CGV, alcançando égide. A partir de experiências de outras cadeias, empresas e países, surgem insights para a cadeia leiteira de Palmas. Daly et al. (2018) ao estudarem a CGV do café Arábica na Jamaica, ressaltaram que é positivo estudar os caminhos percorridos por empresas para atingirem o upgrading em diferentes regiões, procurando identificar as estratégias usadas por essas para que atualmente sejam valorizadas e ocupem posições de destaque na cadeia.

Diversas pesquisas apontam o upgrading como estratégia para aumentar competitividade, agregar valor e se manter na atividade com um retorno financeiro adequado, além de tornar as cadeias de valor mais sustentáveis (FERNANDEZ-STARK et al., 2016a, FERNANDEZ-STARK et al., 2016b; LOWE e GEREFFI, 2009; MENDONÇA e PEDROZA FILHO, 2019; POLASTRINI et al., 2020).

O leite é uma bebida que é frequentemente atacada pelas mídias sociais e grupos de interesses especialmente privados, juntamente com toda a cadeia leiteira. O melhor caminho é a comunicação adequada da verdade a respeito e a busca constante por melhorias nos sistemas de produção, escutando as dúvidas, críticas e as preferências do consumidor. Produzir um leite com características desejadas e buscadas pelo consumidor alavanca o upgrading.

\section{CERTIFICAÇÕES COMO CAMINHO PARA O UPGRADING}

A literatura aponta que aspectos a jusante direcionam as etapas produtivas a montante da cadeia, levando ao upgrading dentro da CGV (FERNANDEZSTARK et al., 2016a; LOWE e GEREFFI, 2009).
Um dos caminhos mais recomendados para o ganho em competitividade, agregação de valor e outros benefícios é a diferenciação por meio de selos culturais, sociais ou ambientais (PEDROZA FILHO et al., 2015). A certificação da propriedade e do sistema produtivo proporciona uma diferenciação dentro da cadeia e tende a agregar mais valor a produção, constituindo-se em uma trajetória interessante para o produtor trilhar com a finalidade de chegar ao upgrading. Com as questões ambientais no centro de importantes debates, certificações que garantam responsabilidade e sustentabilidade ambiental ganham a tônica nesse mercado polissêmico. Marchi e Maria (2019) destacam o papel do upgrading ambiental, o que pode ser alcançado por adequações na produção e aquisição de certificação específica.

A preocupação da sociedade com a finitude dos recursos ambientais, os impactos da ação do homem no planeta e uma alimentação mais saudável, embora sejam considerados clichês, agudizam a busca por novas alternativas aos sistemas de produção tradicionais e, no caso de Palmas, majoritariamente informal.

Para tal, é imprescindível a formalização da atividade, seja a nível municipal, estadual e federal, ou seja, por meio do selo de Inspeção Municipal, Estadual ou Federal (S.I.M., S.I.E. e S.I.F.), respectivamente. A partir destes, certificações específicas como leite A2 e Produto Orgânico podem ser obtidas. Não serão abordadas e discriminadas as diversas possibilidades de certificações existentes devido a extensão de laudas que demandaria. Foco maior será dado a estas duas opções.

No que se trata de alimentação saudável, o leite A2 tem recebido maior atenção, embora os benefícios ainda sejam pouco conhecidos pela população em geral. Todas as fêmeas mamíferas produziam leite com 
a proteína com a variante A2. Porém, apenas fêmeas bovinas sofreram mutação e passaram a produzir a variante A1 ou ambas. Foi verificada que em raças bovinas asiáticas e africanas, puras, essa mutação está pouco presente ou mesmo ausente (BROOKETAYLOR et al., 2017; MISHRA et al., 2009).

Mishra et al. (2009) realizaram estudo pioneiro em raças indianas e também em bubalinos. Foram genotipados 618 animais de 15 raças zebuínas e 231 bubalinos de 8 raças diferentes. Os resultados encontrados foram surpreendentes e evidenciaram que a variante A2 é alta nas raças zebuínas $(0,987)$. Nos bubalinos, todas as 8 raças possuem unicamente a variante $\mathrm{A} 2$.

Embora ainda não haja um consenso na comunidade científica sobre os efeitos da proteína A1 no organismo humano, transtornos gastrointestinais, alterações pancreáticas e outras doenças tem sido associadas a tal proteína (BARBOSA et al., 2019; MISHRA et al., 2009). A diferença está em um aminoácido na posição 67 dos 209 aminoácidos. Embora pareça uma diferença mínima, ao ser digerida a proteína A1 dispensa um resíduo de histidina, que "favorece a liberação do peptídeo opioide $\beta$ casomorfina-7 (BCM-7)" (BARBOSA et al., 2019, p.2). Adicionado a isso, o alelo A2 também está associado com a maior produção de leite, menor conteúdo de gordura no leite e mais proteína, representando benefícios adicionais à seleção de animais homozigotos A2 tanto para o produtor quanto para indústria e consumidor (RAHIMI et al., 2015).

Em indivíduos mais sensíveis, sintomas como inchaço abdominal, inflamação gastrointestinal, dor e alteração na consistências das fezes podem ser observados (BARBOSA et al., 2019; BROOKETAYLOR et al., 2017). Jianquin et al. (2016) confirmaram essas hipóteses em estudo randomizado e estratificado com a população Han chinesa. Os resultados evidenciaram que o consumo de leite A1 aumentou a inflamação e piorou os sintomas gastrointestinais. Embora não sejam fartos, estudos recentes têm demonstrado vantagens do consumo de leite com proteínas apenas A2 (BARBOSA et al., 2019; BROOKE-TAYLOR et al., 2017; JIANQUIN et al., 2016).

No que diz respeito a produção orgânica, esta vai além da produção de um alimento mais saudável. Pois a normatização inclui questões sociais, ambientais e o bem-estar animal. No sistema orgânico há a preocupação com a ética no cuidado com os animais, os direitos e seguridade aos trabalhadores, a sustentabilidade do sistema, entre outros pontos citados na legislação. A Lei ${ }^{\circ} 10.831$, de 23 de dezembro de 2003, esclarece que esse sistema é

[...] todo aquele em que se adotam técnicas específicas, mediante a otimização do uso dos recursos naturais e socioeconômicos disponíveis e o respeito à integridade cultural das comunidades rurais, tendo por objetivo a sustentabilidade econômica e ecológica, a maximização dos benefícios sociais, a minimização da dependência de energia não-renovável, empregando, sempre que possível, métodos culturais, biológicos e mecânicos, em contraposição ao uso de materiais sintéticos, a eliminação de uso de organismos geneticamente modificados e radiações ionizantes, em qualquer fase do processo de produção, processamento, armazenamento, distribuição e comercialização, e a proteção do meio ambiente (BRASIL, 2003).

A principal motivação para o consumo de produtos orgânicos é o fato da percepção do consumidor de que estes são mais saudáveis (ORGANIS \& MARKET ANALYSIS, 2017). Para o setor produtivo, Mendonça e Pedroza Filho (2019) constataram ainda benefícios como maior estabilidade dos preços dos orgânicos frente a produtos oriundos de sistemas convencionais, descomoditização, redução 
dos players, maior organização dos produtores, aperfeiçoamento da cadeia, ou seja, upgrading por processo.

Neste cenário que se desenhou, "o Brasil é o país com o maior mercado orgânico do continente", declaram Willer e Lernoud (2019, p. 28). Soma-se a isso o fato de o país já ter um selo que distingue sua produção orgânica. Dados levantados pelo Ministério da Agricultura, Pecuária e Abastecimento (MAPA, 2019) registraram um crescimento de $300 \%$ no número de produtores orgânicos em menos de uma década (2010 - 2018). Atualmente o Brasil possui 17.730 produtores e mais de 22 mil unidades de produção orgânica, sendo que em 2012 haviam menos de 6 mil produtores e pouco mais de 11 mil unidades produtivas (MAPA, 2019).

O sul do Brasil ainda é destaque quando se fala em orgânicos. No estado do Tocantins não há nenhum registro atualmente de produtor orgânico no Cadastro Nacional de Produtores Orgânico (VILELA et al., 2019). Todavia, produtos orgânicos de outras localidades são comercializados em supermercados, hipermercados e lojas de produtos naturais da capital, evidenciando um nicho de que não é atendido pela produção local.

O início do desenvolvimento da produção orgânica no Brasil se deu nos anos 1990. Até então não havia uma normatização específica no país para esse sistema de produção. A certificação era regulada apenas pelas certificadoras. Somente na década seguinte, nos anos 2000, que o sistema orgânico foi normatizado por lei federal específica, o que foi o grande passo para o crescimento do sistema orgânico no país.

O Decreto $n^{\circ}$ 6.323, de 27 de dezembro de 2007 regulamentou a Lei ${ }^{\circ} 10.831$ que normatizou a agricultura orgânica (BRASIL, 2003; BRASIL, 2007).
Foi instituído o Sistema Brasileiro de Avaliação da Conformidade Orgânica (SisOrg). Este é integrado pelos Sistemas Participativos de Garantia de Qualidade Orgânica e pela Certificação por Auditoria. Posteriormente, a Instrução Normativa $\mathrm{n}^{\circ} 46$ do Ministério da Agricultura, Pecuária e Abastecimento, de 6 de outubro de 2011, estabeleceu o regulamento técnico para os Sistemas Orgânicos.

Esta foi alterada e atualizada ainda pela Instrução Normativa ${ }^{\circ}$ 17, de 18 de junho de 2014. Ambas norteiam a produção em conversão ou Sistemas Orgânicos de Produção já estabelecidos, definindo as normas para o sistema (BRASIL, 2011; BRASIL, 2014). Em resumo, tratam de regulamentação e das práticas de manejo e substâncias permitidas ou não no Sistema Orgânico de Produção. O selo SisOrg garante que o produto é oriundo de sistema orgânico certificado (Figura 1).

Figura 1. Selo SisOrg que identifica e garante a qualidade dos produtos orgânicos no Brasil.

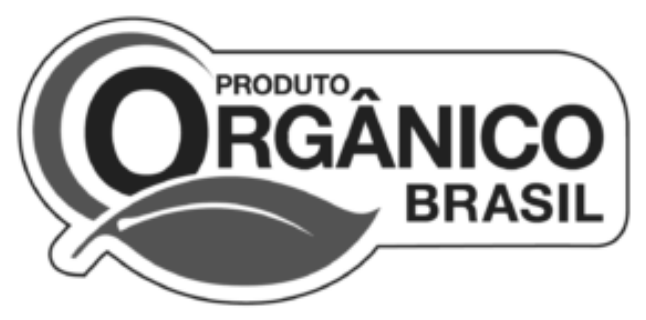

Fonte: Selo SisOrg MAPA (2009).

Em 2012 um novo avanço: foi instituída a Política Nacional de Agroecologia e Produção Orgânica (PNAPO), por meio do Decreto ${ }^{\circ}$ 7.794, de 20 de agosto de 2012 (BRASIL, 2012). O objetivo do Decreto foi "integrar, articular e adequar políticas, programas e ações indutoras da transição agroecológica e da produção orgânica e de base agroecológica, contribuindo para o desenvolvimento sustentável e a qualidade de vida da população, por meio do uso 
sustentável dos recursos naturais e da oferta e consumo de alimentos saudáveis" (BRASIL, 2012). Conforme Lima et al. (2020), o PNAPO tem sido referência para outros países, servindo de modelo de sistema "alternativo" de produção em contraposição ao modelo convencional monopolista e latifundiário, que é o predominante no Brasil e em alguns outros países.

A qualidade dos produtos orgânicos é garantida de três modos pela legislação brasileira: Certificação por auditoria, Sistema participativo e o Controle Social (OCS). No caso a certificação por auditoria, o produtor precisa contratar o serviço de uma certificadora, seja uma empresa pública ou privada, nacional ou internacional. Uma vez que ainda não há uma empresa pública cadastrada para essa função na região, o caminho é a contratação de uma empresa certificadora privada, o que é considerado bastante oneroso, dificultando o acesso de pequenos produtores a essa via de conversão do sistema produtivo. Adiciona-se ainda o custo de deslocamento, uma vez que o estado está distante dos escritórios e dos fiscais das certificadores.

Na certificação por auditoria o produtor recebe o selo de orgânico ao final do processo e pode comercializar seus produtos livremente em mercados, supermercados ou repassar a terceiros. Este é o modo mais comum adotado no Brasil quando se trata da produção animal orgânica (VILELA et al., 2019).

Já o Organismo Participativo de Avaliação da Conformidade - OPAC "é uma organização que assume a responsabilidade formal pelo conjunto de atividades desenvolvidas num Sistema Participativo de Garantia - SPG, constituindo na sua estrutura organizacional uma Comissão de Avaliação e um Conselho de Recursos, ambos compostos por representantes dos membros de cada SPG" (BRASIL, 2011, p.2). A terceira forma de garantia é a Organização de Controle Social se trata de um
[...] grupo, associação, cooperativa, consórcio com ou sem personalidade jurídica, previamente cadastrada no MAPA, a que está vinculado o agricultor familiar em venda direta, com processo organizado de geração de credibilidade a partir da interação de pessoas ou organizações, sustentando, sustentado na participação, comprometimento, transparência e confiança, reconhecido pela sociedade (BRASIL, 2011).

Atualmente são 36 OAC credenciadas, onde 25 são SPG e onze são certificadoras por auditoria no país.

\section{MATERIAIS E MÉTODOS}

Os instrumentos de coleta de dados secundários foram a pesquisa bibliográfica e documental. Estes permitiram esmiuçar a literatura em busca de outras experiências e relatos, certificações existentes e formas de upgrading em outras cadeias estudados ao redor do mundo. A coleta de dados primários desenvolveu-se por meio de entrevistas semiestruturadas junto aos atores da cadeia leiteira de Palmas e de outros municípios do estado de Tocantins que comercializam seus produtos nesta cidade. Foram entrevistados um total de 58 atores, em outubro de 2019: 40 produtores sendo 32 da agricultura familiar, 1 laticínio agroindustrial, 5 gerentes de super e hipermercados, 2 fiscais de inspeção sanitária (um municipal e um estadual), 2 gerentes de agências bancárias e 8 profissionais do setor (eng. agrônomos, médicos veterinários, técnicos e zootecnistas), autônomo ou servidor público de órgãos relacionados à atividade como a Agência de Defesa Agropecuária Adapec, o Instituto de Desenvolvimento Rural do Tocantins - Ruraltins, a Secretaria de Agricultura, Pecuária e Aquicultura - Seagro e a Secretaria Municipal de Desenvolvimento Rural - Seder.

As entrevistas aconteceram presencialmente e in loco e foram gravadas com a autorização dos 
entrevistados, favorecendo assim a transcrição fidedigna e detalhada para posterior análise.

Para o grupo com maior número de atores, o de produtores, a amostragem foi do tipo Snow Ball e o fechamento da amostra se deu pela técnica da saturação teórica. Na amostragem Snow Ball cada entrevistado localizado e contatado faz a indicação ou sugestão de outros atores, orientando as entrevistas para novos tecidos sociais dentro da cadeia, às vezes modificando a via das entrevistas e mesmo do estudo (HANDCOCK e GILE, 2011). Já a saturação teórica é utilizada em pesquisas qualitativas com a finalidade de dar rigor científico à amostragem não probabilística. Consiste na coleta de dados até que cesse o aparecimento de novos dados ou informações, ou seja, "é usada para estabelecer ou fechar o tamanho final de uma amostra" (FONTANELLA et al., 2008, p.17). O termo "é uma metáfora advinda da área físico-química [...]. Diz-se que uma solução está saturada quando a concentração do soluto é a máxima possível [...]" (FONTANELLA e MAGDALENO JÚNIOR, 2012, p. 64).

A saturação teórica para o grupo produtores foi atingida na décima entrevista e a constatação da saturação teórica foi realizada por meio do modelo adotado por Falqueto et al. (2018). Os autores recomendam prosseguir com mais algumas entrevistas após a saturação para confirmá-la. Devido ao número pequeno de produtores cadastrados na Seder, optou-se por dar continuidade às entrevistas até o momento em que as indicações dos entrevistados apontassem para aqueles que já haviam sido entrevistados, ou seja, na quadragésima entrevista. Esse prosseguimento das entrevista permitiu o fortalecimento da constatação da saturação teórica.

A etapa de análise dos dados se iniciou com a transcrição das entrevistas para planilhas de Excel visando a compilação dos dados primários, permitindo assim uma estruturação de acordo com o assunto abordado e ator entrevistado. Em seguida os dados estruturados por tema foram analisados criteriosamente tendo por base os pressupostos teóricos da abordagem de Cadeia Global de Valor, em especial com relação aos conceitos de upgrading.

Verificou-se que a metodologia adotada foi plausível e adequada para este estudo, permitindo conhecer o cenário da cadeia do leite em Palmas, seus atores, as certificações existentes, os gargalos a sua implantação nas demais propriedades e quais as outras certificações que podem levar a um upgrading do produtor e da cadeia palmense. As entrevistas permitiram conhecer a realidade local, as legislações vigentes, as estratégias de agregação de valor adotadas pelos produtores.

As pesquisas bibliográfica e documental foram pilares importantes nesse sentido, pois permitiram conhecer diferentes certificações existentes, sua demanda, dados acerca de cada uma dessas, bem como certificações implantadas em outras regiões ou mesmo em outras cadeias e que se constituíram em estratégias viáveis de upgrading.

\section{RESULTADOS E DISCUSSÃO}

Constatou-se que o campo teórico de CGV foi oportuno e eficaz como caminho para se alcançar o objetivo traçado inicialmente, permitindo que fossem elencadas certificações que tem potencial de upgrading aos produtores de leite. Também foi adequado para responder ao questionamento que norteou este estudo, qual seja: Quais certificações podem promover o upgrading ao produtor de leite?

As revisões bibliográficas e documentais permitiram investigar como outras cadeias conseguiram alavancar dentro da $\mathrm{CGV}$, quais 
certificações foram importantes nesse processo e quais características adicionais favoreceram o upgrading.

\section{Principais gargalos da cadeia do leite em Palmas - TO}

A informalidade é alta na cadeia leiteira de Palmas. Esse resultado é semelhante ao encontrado por Polastrini et al. (2020). Os resultados da pesquisa apontaram que $77,5 \%$ (31) dos produtores comercializam sua produção informalmente. Registrou-se que $10 \%$ dos produtores estão de acordo com a legislação vigente sendo que destes $5 \%$ entregam sua produção ao único laticínio agroindustrial e os outros $5 \%$ possuem o S.I.M. enquadrado como produção artesanal por ser em pequena escala, industrializando a produção e comercializando em supermercados e outros estabelecimentos e feiras da capital.

Quando os produtores foram interrogados sobre a formalização, houve relatos de dificuldades tangíveis. A maioria (95\%) relatou o alto custo de produção como fundamento da informalidade. Em razão disso, os produtores não passam sua produção ao laticínio, pois o "preço pago pelo litro de leite é equivalente ao custo de produção", relatou o produtor 3. O laticínio paga entre $\mathrm{R} \$ 0,90$ a 1,20 pelo litro de leite in natura. Todavia, nenhum produtor entrevistado realizou uma análise refinada para conhecer o custo real de produção, declarando "ser por volta de R $\$$ 1,10 ”, “deve estar em R $\$ 1,30$ ”, "eu acredito que seja mais de R\$ 1,00", nos fragmentos de entrevistas sobre o custo de produção por litro de leite produzido. Assim sendo, nenhum dos entrevistados sabe exatamente qual o seu custo de produção, pois foram apresentadas apenas estimativas.

Por outro lado, os fiscais entrevistados capitulam que falta à etapa de produção uma melhor produtividade "para que a competitividade seja maior e, por tanto, haja uma rentabilidade maior", explicou o fiscal 1. Na fala de ambos fiscais, a legislação não é burocrática ou demasiado exigente, pois trata de pontos importantes para garantirem a qualidade e segurança dos produtos lácteos comercializados. "Estamos dispostos a auxiliar o produtor no que ele precisar, sanar dúvidas quanto a formalização, estruturas necessárias, orientar", comentou o fiscal 2, mas acrescentou que os produtores geralmente começam as modificações para "formalização na propriedade por conta própria, sem ler a legislação ou consultar um profissional e acaba fazendo algo fora do aceitável pela legislação". Durante entrevistas aos produtores, os autores observaram esse desconhecimento dos procedimentos para a formalização da atividade e certificações, pois genericamente o produtor acha "tão difícil que é quase impossível conseguir regularizar a situação", afirmou um dos produtores.

A formalização permite a venda livre na capital, agregando maior valor aos produtos e abrindo novos canais de escoamento da produção como restaurantes, lanchonetes, bares, mercados de bairro e até mesmo supermercados. Nesse sentido, as entrevistas aos gerentes de hipermercados concatenaram à pesquisa, permitindo-se ratificar a relevância do estudo. De acordo com os servidores entrevistados (SEDER, Seagro e Adapec), não há um registro oficial do consumo de leite em Palmas. Uma lacuna que é importante ser preenchida para que se possa identificar o potencial do município em absorver evoluções na produção local.

Todavia, através das entrevistas aos gerentes de hipermercados, constatou-se que há uma média de venda nestes estabelecimentos equivalente a $350 \mathrm{mil}$ litros de leite por mês. 
Em razão destes serem hipermercados de rede, todos os produtos lácteos são originários de outros estados. Acrescente-se que o consumo de lácteos é bem maior, pois há o mercado informal (que por sinal é grande) e os mercados intermediários que compram lácteos dos produtores e comercializam a produção formal localmente. Em ambos os casos a preferência do consumidor é quem dita o volume de aquisição dos produtos lácteos e suas características.

É importante destacar que $80 \%$ dos produtores de leite que comercializam a produção, são da agricultura familiar. Dados do SIDRA evidenciam que a maior parte dos produtores palmenses são de subsistência. Dos 303 estabelecimentos que produzem leite, apenas 80 comercializam a produção e 64 são da agricultura familiar (SIDRA, 2020).

Entre os entrevistados também verificou-se que a maioria eram da agricultura familiar (80\%). Esses dados reforçam a relevância da cadeia do leite em âmbito social. Também Polastrini et al. (2020) observaram que um percentual expressivo de pequenos produtores na cadeia do leite em Palmas, destacando que esta não era a principal fonte de renda das famílias produtoras, mas representa um renda complementar.

\section{Estratégias de upgrading para a cadeia do leite em Palmas - TO}

Diante desse cenário identificado pela presente pesquisa e articulando-a às perspectivas locais e mundiais de CGV de lácteos e outras cadeias agroalimentares, algumas das principais certificações diagnosticadas foram: S.I.M., S.I.E., Selo Artesanal, Produto Orgânico e Leite A2. Devido a extensão do assunto, este trabalho se limitará a tratar dessas formas de certificação. Porém, há um vasto portfólio de certificações que estão sendo cada vez mais buscadas e valorizados pelos diferentes elos das cadeias de valor.
Dois produtores de leite entrevistados estão formalizados e possuem o S.I.M. Em razão do processo inerente à certificação, tais produtores apresentaram maior conhecimento sobre a legislação e maior capacitação produtiva. Estes industrializam a produção de leite enquadrando-se ainda no Selo Artesanal, conquista a partir da Lei ${ }^{\circ} 1.228$, de 23 de outubro de 2003 (PALMAS, 2003).

Atualmente existem quinze produtores artesanais abrangendo diferentes atividades produtivas no município de Palmas. A "Lei do Artesanal" representa um avanço importante para a produção local, pois leva em consideração as condições regionais e a realidade do pequeno negócio. Em contrapartida, há limitações. Para que o produtor obtenha o Selo Artesanal é preciso, no caso da produção láctea, que a produção seja em pequena escala, de até 100 litros/dia, além de outros pontos discriminados nesta Lei.

Em entrevista, os produtores formalizados através do Selo Artesanal afirmaram que o processo de “certificação não foi tão difícil e burocrático e que compensa o investimento". O primeiro a se formalizar foi pioneiro e já coleciona quase 20 anos de certificação. De acordo com o produtor "o início foi muito mais complicado, pois não havia nem mesmo um modelo de laticínio, tendo eu mesmo criado o meu". O fiscal 1 explica que

$\mathrm{O}$ produtor é muito resistente as exigências e considera tudo muito difícil e desnecessário [...]. Só que toda a base legal é muito antiga, foi criada em 1950. Seja a nível municipal, estadual ou federal, as exigências são semelhantes [...]. A grande diferença é que a nível municipal e estadual há uma politização muito forte que dificulta ou facilita a obtenção dessa certificação.

Também o fiscal 2 salientou que o Regulamento da Inspeção Industrial e Sanitária de Produtos de Origem Animal (RIISPOA), Lei ${ }^{\circ} 1.283$, 
de 18 de dezembro de 1950 (BRASIL, 1950), é o principal instrumento que ainda hoje norteia a formalização da produção animal em todo o país. Em 29 de março de 2017 houve a sua atualização pelo Decreto $\mathrm{n}^{\circ}$ 9.013, passando a abordar questões em pauta na atualidade, como o bem-estar dos animais de produção e o transporte humanizado (BRASIL, 2017).

Fernandez-Stark et al. (2016b) ressaltam que há vários caminhos para o upgrading, dentre as quais melhorias com relação ao produto, processamento, aumento da produtividade, diversificação e inovação são oportunidades significativas. Para o produtor de leite, a busca por orientação profissional, conhecimento da legislação e do processo de certificação, linhas de crédito para financiamento e maior nível técnico e tecnológico do sistema produtivo em si já representam ganhos potenciais e maior chance de upgrading dentro da cadeia.

Uma opção plausível ao produtor de leite é o S.I.E. que também apresenta a Lei do Artesanal a nível estadual, a Lei $\mathrm{n}^{\circ} 1.896$, de 28 de fevereiro de 2008 (TOCANTINS, 2008). Conforme relatado pelos fiscais entrevistados, não há muita diferença em relação aos investimentos em instalações. A nível municipal estima-se que o custo de instalação seja entre 50 e 60 mil reais com a construção do laticínio e aquisição dos equipamentos necessários ao processamento do leite. A vantagem da Lei do Artesanal a nível estadual consiste no limite de produção diária ser maior, podendo atingir 300 litros/dia, ou seja, limite três vezes superior ao permitido a nível municipal. A legislação preconiza que esta certificação é destinada para produtores em pequena escala que preservem as "características tradicionais, culturais ou regionais dos produtos lácteos" (TOCANTINS, 2008).

O leite A2 é outra estratégia de agregação de valor bastante dissuasiva e que tem ganhado cada vez mais espaço no mercado lácteo nacional e internacional. Apesar do leite de vaca ser o mais consumido, é também o que mais sofre pressões da sociedade e dos profissionais da saúde. Isso se deve ao fato, como descrito anteriormente, de fêmeas bovinas serem as únicas a terem sofrido uma mutação genética que fez com que passassem a produzir leite com proteína A1 ao invés de A2 ou ambas (BARBOSA et al., 2019).

No Brasil, o leite A2 era praticamente desconhecido mesmo entre técnicos e profissionais. Atualmente se observa um crescimento da produção de leite A2, do interesse da sociedade em realizar a aquisição de um produto tido como mais saudável e de profissionais e pesquisadores em estudar e conhecer melhor os benefícios do leite $\mathrm{A} 2 \mathrm{e}$ avaliar as vantagens mercadológicos do produto. Isso confere ao leite A2 um preço até três vezes superior ao leite convencional, o A1 ou A1/A2.

Em Palmas, apenas 10\% (4) dos produtores entrevistados tinham conhecimento do leite A2A2. Provavelmente isso se deve ao fato dos produtores terem pouca assistência técnica e/ou essa orientação não tem sido efetiva. No SIDRA (2020) documenta-se que $64 \%$ dos produtores não recebem assistência técnica. Já os resultados deste estudo revelaram que $55 \%$ dos produtores entrevistados não receberam assistência técnica, resultado um pouco melhor que os documentados pelo SIDRA, que abrange todos os produtores registrados. Todavia, Palmas apresenta uma logística favorável, concentra instituições de pesquisa e ensino superior, sedia eventos relacionados ao setor leiteiro e é sede ou possui escritórios de órgãos dos governos estadual e federal, além do municipal obviamente, ou seja, os resultados poderiam ser melhores. 
Foi diagnosticado ainda que a maioria dos produtores (90\%) possuem rebanhos mestiços (ou mesmo raças oriundas de cruzamentos) ou mistos, o que pode dificultar o processo de genotipagem e seleção do rebanho para produção futura de leite com proteína A2 ao invés de A1 ou A1/A2. Um produtor entrevistado $(2,5 \%)$ trabalha com a raça Gir Leitira pura, sendo um dos maiores produtores do município, um dos mais antigos e com um dos maiores rebanhos leiteiros. Este tem um potencial expressivo de já estar produzindo leite quase que exclusivamente A2 em razão de sua origem asiática, como explicam BrookeTaylor et al. (2017).

Dois produtores $(5 \%)$ entrevistados possuíam rebanho Jersey, outra raça interessante para a produção do leite A2. No estudo de Duarte-ázquez et al. (2017), vacas da raça Jersey genotipadas apresentaram frequência do alelo A2 de 0,858 . Para os produtores que possuem rebanhos dessas raças citadas, a trajetória relativamente longa de certificação está mais tangível. Mesmo estando na informalidade ou no processo de formalização e certificação, o produtor poderia agregar mais valor aos seus produtos e trabalhar na divulgação, mesmo que apenas para seus atuais clientes, dos benefícios do leite dessas raças.

$\mathrm{O}$ mercado para o leite A2 é promissor, mas a certificação é onerosa. Também não há políticas públicas e assistência técnica prontamente disponível ao produtor de leite, especialmente ao pequeno e descapitalizado. Para médios e grandes produtores é uma alternativa interessante de agregação de valor, visto que o produto final apresenta um valor bem superior ao praticado no mercado com o leite convencional e estes produtores tem capital para investir no processo de transição para produção de leite unicamente A2.
Os custos envolvem os testes genéticos do rebanho leiteiro e inseminação artificial com sêmen de touros homozigotos A2A2. Além disso, o processo leva tempo e há ainda os custos da certificadora. Para produtores que possuem rebanhos leiteiros que são quase que exclusivamente A2, há um ganho de tempo e redução de custos consideráveis. Gradinaru et al. (2017) destacam a importância das raças rústicas, nativas e daquelas ameaçadas de extinção, para o futuro da pecuária, pois além de representarem a solução para problemas futuros, possuem menor prevalência do alelo A1.

A raça Gir Leiteira tem se destacado nesse sentido, pela sua adaptabilidade às condições climáticas do Brasil, qualidade do seu leite, tanto com relação à proteína como a outros sólidos do leite e ainda, a maior prevalência do alelo A2 (DUARTEÁZQUEZ et al., 2017; GRADINARU et al., 2017;). Há registros no Brasil de produtores que focaram nesse nicho de mercado "alternativo", "saudável" ou "especial", abarcando ainda a produção de um leite apenas A2A2 e, adicionado a isso, aderiu ao sistema orgânico e produção de lácteos sem lactose, por exemplo. Assim capturaram nichos de mercados que ainda não eram atendidos pelos demais produtores.

Um dos produtores de leite entrevistados apresentava rebanho quase exclusivamente da raça nativa do Brasil, a Curraleira. A produção de um leite oriundo exclusivamente de uma raça nativa do país, se constitui em uma estratégia de agregação de valor ao leite e derivados, seja pela qualidade, questões ambientais, culturais ou sociais. Neste contexto, outros aspectos podem ser mais bem explorados, como a alimentação do gado.

Faccia (2020) destacou que o leite de vacas alimentadas com pastagem é cada vez mais apreciado pelo consumidor. As razões para essa valorização 
envolvem a sustentabilidade ambiental, bem-estar animal, valores éticos (vantagens cientificamente comprovadas) e melhor composição do leite, mais saudável e possivelmente com características sensoriais diferenciadas (ainda sendo investigadas) (CABIDDU et al., 2019; FACCIA, 2020). Cabiddu et al. (2019) destacam que o leite de vacas a pasto é mais rico nutricionalmente, possuindo mais vitaminas, polifenóis, enzimas e até mesmo ácidos graxos, contribuindo com a saúde humana. Os autores ainda acrescentam que os benefícios se estendem para além dos aspectos nutricionais, abarcando a redução dos custos de produção, que é um dos pontos mais sensíveis da cadeia leiteira de Palmas, bem como a continuidade do produtor no sistema extensivo de forma sustentável e viável economicamente. Dessa forma, problemas em pauta nas discussões atuais, como o êxodo rural, desemprego, degradação ambiental e altas taxas de urbanização, poderiam ser amenizados (UNITED NATIONS, 2018).

Uma diferenciação desse tipo pode implicar ganhos em competitividade, ou seja, uma ferramenta a ser mais bem analisada e trabalhada. Essa é uma possibilidade viável para os produtores locais, uma vez que no período chuvoso todos os animais se alimentam basicamente de pastagens e no período seco isso não é possível em razão da maioria das propriedades não possuir uma estrutura suficiente para garantir a dieta a pasto para as vacas em produção. Também há propriedades ainda com pastagens nativas, algo que pode somar uma maior valorização aos produtos.

O fato observado é que em todos os casos é preciso que o Poder Público elabore políticas públicas voltadas para essa produção alternativa, focando em estratégias de upgrading para os produtores. Devido aos aspectos culturais, ao baixo nível de escolaridade dos produtores, a falta de capital para investir e a desunião da classe produtora (POLASTRINI et al., 2020).

A última certificação diagnosticada como potencial para o upgrading dos produtores de leite é a de Produto Orgânico. A produção orgânica está cada vez mais reconhecida por suas vantagens à saúde humana e a todo o meio ambiente e é uma forte tendência mundial. A conversão do sistema convencional para o orgânico é um opção ao produtor palmense, possibilitando a entrada em novos mercados e uma maior agregação de valor aos produtos lácteos.

Ballestero et al. (2019) concluíram que, com relação ao café orgânico, se destaca no consumo e valorização do produto o consumidor com renda mais elevada. Nesse sentido Palmas possui a população com a maior renda per capita, o que evidencia o potencial do município para o consumo de produtos orgânicos.

Mendonça e Pedroza Filho (2019) adotaram o campo conceitual de CGV para analisar mudanças na cadeia do cacau após a transição do sistema convencional para o orgânico. Conforme os autores, para atender um mercado mais exigente os produtores converteram o sistema de produção, o que exigiu capacitação da mão de obra e melhorias nas técnicas de manejo das plantas e das amêndoas. Essa capacitação é necessária aos produtores de leite pois o Sistema Orgânico é mais complexo.

Atualmente não há nenhuma propriedade com produção de leite orgânica no município, mas alguns produtores (5) manifestaram interesse em conhecer e/ou migrar para o Sistema Orgânico de Produção. Possivelmente esse baixo número de interessados seja em razão de poucos acreditarem e conhecerem o mercado para produtos alternativos ou especiais e também devido aos aspectos culturais já consolidados. Foi constatado durante as entrevistas afirmações que homogeneízam o consumidor, sendo que há 
consumidores com necessidades, valores e gostos diferentes, o que pode ser melhor aproveitado pelos produtores como forma de aumentar a competitividade e valor dos seus produtos.

Duas opções mais plausíveis e acessíveis aos produtores de leite de Palmas são por meio da OCS e a SPG. Porém, necessitam de uma organização social, mobilização da comunidade, interesse dos atores envolvidos e o conhecimento a respeito das vantagens do sistema orgânico nos aspectos social, ambiental e econômico. Na OCS, é permitido ao produtor orgânico comercializar a produção apenas de forma direta, não podendo passar a terceiros a etapa de comercialização. Também é livre a comercialização de forma direta a programas do governo ou diretamente ao consumidor final, como em feiras livres. Mas como a maioria dos produtores entrevistados são pequenos e a mão de obra é familiar, essa limitação não refletiria em um problema incapacitante. Outro aspecto positivo da OCS é que esta não é onerosa, o que é muito relevante haja visto que os produtores se declararam descapitalizados para investimento básicos como pastagens, cercas e aquisição de matrizes, inviabilizando gasto apenas com certificação.

Poucos órgãos ou instituições fornecem informações sobre o processo de conversão da produção convencional para o Sistema Orgânico. Em Palmas, dois órgãos possuem profissionais para orientar o produtor nesse sentido: MAPA e Ruraltins. Ambos tem um papel relevante de informação e orientação em todo o processo. No Ruraltins há um servidor público que conduz e orienta os produtores interessados em fazer a transição para o sistema orgânico.

O MAPA é responsável por gerir o SisOrg e, no caso de OCS, esta precisa estar registrada no órgão. O Ruraltins orienta quanto aos procedimentos necessários à conversão do sistema de produção, esclarece dúvidas, fornece o modelo de projeto que deve ser apresentado pelo produtor, onde ele detalhará todos os pontos do seu sistema de produção orgânico como manejo sanitário, mudanças que serão realizadas na propriedade, origem dos insumos permitidos, entre outros. Este é o chamado Plano de Manejo Orgânico e deve incluir ainda o histórico de utilização da área, manutenção ou incremento da biodiversidade, manejo dos resíduos, conservação do solo e da água, manejo de produção vegetal e animal. Ao ser aprovado em uma das modalidades descriminadas pela legislação, se dá início ao processo de conversão primeiramente da propriedade e depois da produção animal e vegetal. O tempo de conversão é relativo, dependendo de vários fatores que são pormenorizados na legislação, mas pelo menos dois anos são necessários para esse processo de transição.

Todo o material necessário está disponível na página do MAPA na internet, onde é possível realizar download de manuais, formulários e também assistir à vídeos explicativos, acessar o Cadastro Nacional de Produtores Orgânicos, bem como consultar a relação de Organismos de Avaliação de Conformidade Orgânica mais próximos da propriedade, Plano de Trabalho do MAPA, Caderno do Plano de Manejo Orgânico, lista de produtos fitossanitários aprovados para o sistema orgânico, tópicos com perguntas e respostas, manuais de controle de pragas e doenças e modelos de fichas agroecológicas.

Em âmbito financeiro o produtor está descapitalizado e precisa de financiamento para formação de pastagens, reforma de cercas, aquisição de matrizes e outras melhorias necessárias. Todavia, nenhum dos entrevistados tiveram acesso recente a linha de crédito. Aqueles que já tiveram acesso, obtiveram há 5 a 10 anos atrás. Muitas reclamações 
nesse sentido foram relatadas pelos produtores durante as entrevistas.

Com a finalidade de compreender esse ponto e alcançar o objetivo da pesquisa, foram entrevistados os gerentes das duas principais instituições financeiras que fornecem crédito ao pequeno e médio produtor. Os gerentes garantiram que não houve mudança alguma que comprometesse a liberação de crédito. Todavia, ressaltaram que a falta de documentação da terra, a ausência de um projeto viável de produção e, especialmente, de comercialização da produção, compromete a liberação de crédito ao produtor. Para o gerente 2 "não tem como liberar crédito para o produtor vender leite clandestinamente pois ele pode não conseguir honrar seus compromissos com o banco". Novamente, é preciso ações efetivas do Poder Público para resolver as questões que envolvem documentação dos lotes nos assentamentos, ponto nitidamente limitante para o acesso a financiamentos.

Vale destacar que para o produtor chegar à certificação é preciso que uma trajetórias seja trilhada. É preciso que haja interesse, motivação, informação, conhecimento, linhas de crédito acessíveis, assistência técnica e apoio de instituições públicas e privadas. Gereffi e Fernandez-Stark (2016) salientam que “diversas combinações de políticas governamentais, instituições, estratégias corporativas, tecnologias e habilidades dos trabalhadores estão associadas ao sucesso no upgrading" (p. 12, tradução nossa). Também Bamber et al. (2016a) explicam a importância da existência de um "pacote" envolvendo conhecimento, formação de mão de obra qualificada, certificações, melhorias na qualidade dos produtos e de maior nível tecnológico dos atores.

Devido ao cenário local constatado, acrescenta-se ainda a organização dos atores da cadeia, especialmente os produtores. Quando há um compartilhamento de conhecimento, trabalho em equipe, ajuda mútua e espírito de colaboração, maiores são as chances de se atingir metas antes improváveis. Todos os produtores (100\%) afirmaram que a união dos produtores é o melhor caminho para a melhoria do setor. Em contrapartida, todos em seguida expressavam que "isso seria muito difícil", "seria o ideal, mas não dá certo", "todas as tentativas deram errado e sempre há pessoas de má fé" e que "seria impossível".

Ballestero et al. (2019) ressaltaram a existência de assimetria informacional por parte do consumidor de café orgânico. O que se constatou na cadeia do leite em Palmas é uma assimetria informacional também, e talvez mais expressiva, em relação ao produtor. Um esforço do Poder Público investindo em palestras e cursos com foco, primeiramente na desmitificação de alguns pontos da produção orgânica, as vantagens do sistema tanto para produtor quanto para consumidor e meio ambiente, seriam um grande passo, considerando que o que se tem ainda é pouco conhecido. A partir do conhecimento e interesse dos produtores, seria viável alguma mobilização e organização dos produtores no sentido de se fundar e registrar uma OCS.

Em síntese, além de estudos sobre como tornar a distribuição dos valores mais igualitária dentro da cadeia, por meio de upgrading, são necessárias pesquisas orquestradas sobre a governança para uma compreensão da cadeia numa visão Top-Down, o que permitirá uma melhor análise das assimetrias de poder dentro da cadeia do leite palmense. Essas análises a níveis local e global são complementares e indissociáveis, visto que o framework de CGV tem como característica marcante uma visão e análise holísticas da cadeia. Estudos nesse sentido serão fundamentais para o desenvolvimento das cadeias de valor e, especialmente, para o desenvolvimento regional. 
Destaca-se ainda que o cenário pós - COVID19 tende a modificar profundamente as cadeias de valor com a finalidade de torná-las mais resilientes. O colapso nas cadeias de suprimentos durante a pandemia de 2020 evidenciou que as cadeias estão cada vez mais globais e, concomitantemente, também dependentes de economias exportadoras (GEREFFI, 2020). Gereffi (2020, p. 298, tradução nossa) afirma que "a fase de expansão da globalização chegou ao fim e que o cenário que se desenha para o futuro não é uma desglobalização, mas sim uma reglobalização". Esse seria o caminho para uma regionalização das cadeias e para uma estruturação mais sustentável e resiliente (GEREFFI, 2020).

A dinâmica observada na cadeia do leite em Palmas a partir da pandemia de COVID - 19 em 2020, bem como das demais cadeias agroalimentares, foi de valorização das empresas locais, dos produtores e pequenos empresários, pelos governos e pela sociedade. $\mathrm{O}$ preço dos alimentos sofreu alta significativa e a produção local e regional foi vista como a "garantia de segurança" no abastecimento das cidades. Esse processo vivenciado em 2020 chamou a atenção para o desenvolvimento de uma produção animal e vegetal mais regionalizada, mas também mais saudável e sustentável.

\section{CONSIDERAÇÕES FINAIS}

O objetivo levantado inicialmente para o estudo foi alcançado. Por meio da pesquisa, identificou-se certificações plausíveis para a ascendência dos produtores de leite para etapas mais elevadas da cadeia global de valor do leite no município de Palmas. O arcabouço de CGV foi eficaz para atingir o objetivo do estudo, permitindo uma análise minuciosa das possibilidades de upgrading, além de fornecer estruturas importantes para compreender o setor leiteiro palmense. Apesar da cadeia ser local, esta sofre influência substancial das oscilações dos preços, tendências de mercado e consumo a nível global. Também os insumos são frequentemente importados.

A cadeia leiteira de Palmas é marcadamente informal. Apenas dois produtores estão formalizados e outros dois comercializam sua produção no entreposto de beneficiamento. A maior parte dos produtores entrevistados está no mercado informal.

As trajetórias de upgrading trilhadas por firmas, cadeia de valor e países são semelhantes, com algumas nuances envolvendo aspectos particulares de cada região. É irrefutável o papel da ciência, pesquisa, inovação, certificações ambientais e sociais para o upgrading.

Certificações como S.I.M., S.I.E., Selo Artesanal, Selo de Produção Orgânica e Leite A2 formalizam a atividade leiteira e proporcionam segurança e estabilidade para o produtor comercializar sua produção livremente em feiras, supermercados e diretamente ao consumidor. Os selos elencados agregam valor à produção láctea, melhorando o retorno financeiro das famílias produtoras de leite e derivados. Certificações que garantam a preservação ambiental, a sustentabilidade produtiva, a qualidade dos alimentos, a valorização da cultura e os valores sociais, estão cada vez mais sendo valorizados pelo consumidor, sendo um nicho de mercado importante.

Os custos relativos a algum tipo de certificação são onerosos. Por isso, é importante o apoio do Poder Público aos produtores e, especialmente, a união, conhecimento e motivação da classe produtora para que haja efetiva transferência de tecnologias, novas aprendizagens, inovação produtiva, otimismo em relação à atividade e maior poder de barganha junto aos atores de outras etapas da cadeia, tanto para a aquisição 
de insumos a um menor custo como para certificação e comercialização da produção por um valor melhor.

Há uma expressiva assimetria de informação entre os produtores em relação às certificações, o que tem dificultado o interesse e a adesão desses a novas estratégias para se manterem na atividade e melhorarem sua competitividade, produtividade e rentabilidade. Não se pode esperar uma evolução e mudança substancial partida apenas dos produtores nem apenas do Poder Público, mas de ambos concomitantemente. Cada um desempenha um papel diferente para o upgrading dentro da CGV do leite em Palmas.

As principais limitações ao desenvolvimento da pesquisa foram o grande número de atores envolvidos diretamente na cadeia do leite e a sua localização, a recusa de alguns atores em participarem da entrevista e o receio dos entrevistados em receber algum tipo de represaria ou mesmo serem denunciados, embora os autores tenham garantido a segurança e sigilo e o TCLE tenha sido assinado.

Estudos futuros são necessários para preencher as lacunas que este artigo não pode contemplar. Sugere-se pesquisas que abranjam todos os produtores de leite para conhecer o grau real informalidade presente na cadeia leiteira e também o consumo de leite e derivados no município de Palmas. É interessante que sejam realizadas pesquisas que foquem na governança da cadeia de modo a viabilizar estruturas organizacionais coletivas (ex: cooperativas, condomínios, alianças estratégicas, etc.). Esta permitirá o entendimento das assimetrias de poder historicamente existente na cadeia de valor do leite.

\section{AGRADECIMENTO}

Os autores agradecem à Coordenação de Aperfeiçoamento de Pessoal de nível Superior
(CAPES) pela concessão de bolsa de pesquisa ao nível de mestrado. O presente trabalho foi realizado com apoio da Coordenação de Aperfeiçoamento de Pessoal de Nível Superior - Brasil (CAPES) - Código de Financiamento 001.

Todos os autores declararam não haver qualquer potencial conflito de interesses referente a este artigo.

\section{REFERÊNCIAS}

ACETO, M.; MUSSO, D.; CALÀ, E.; ARIERI, F.; ODDONE, M. Role of lanthanides in the traceability of the milk production chain. Journal of Agricultural and Food Chemistry, v. 65, p. 4200, 2017.

BALLESTERO, I.G.; ZIMMERMANN, S.M.V.; DIAS, G.M.; PARO, C.E. Um cafezinho e a conta: a certificação do café orgânico no Brasil. Revista Metropolitana de Sustentabilidade, São Paulo, v. 9, n. 2, p. $67-85$, mai./ago., 2019.

BAMBER, P.; FERNANDEZ-STARK, K.; GEREFFI, G. Peru in the mining equipment global value chain: opportunities for upgrading. Center on Globalization, Governance \& Competitiveness, Duke University, Durham, p. 56, 2016.

BARBOSA, M.G.; SOUZA, A.B.; TAVARES, G.M.; ANTUNES, A.E.C. Leite A1 e A2: revisão sobre seus efeitos no trato digestório. Segurança Alimentar e Nutricional, Campinas, v. 26, p. 1 - 11, 2019.

BRASIL. Decreto ${ }^{\circ}$ 7.794, de 20 de agosto de 2012. Institui a Política Nacional de Agroecologia e Produção Orgânica. Diário Oficial, Brasília, p. 4, 2012.

BRASIL. Decreto ${ }^{\circ}$ 9.013, de 29 de março de 2017. Regulamenta a Lei ${ }^{\circ} 1.283$, de 18 de dezembro de 1950, e Lei $n^{\circ} 7.889$, de 23 de novembro de 1989, que dispõe sobre a inspeção industrial e sanitária de produtos de origem animal. Ministério da Agricultura, Pecuária e Abastecimento. Brasília, DF, 2017.

BRASIL. Decreto $n^{\circ} \mathbf{6 . 3 2 3}$, de 27 de dezembro de 2007. Regulamenta a Lei ${ }^{\circ} 10.831$, de 23 de dezembro de 2003 e dispõe sobre a agricultura orgânica e dá outras providencias. Brasília, DF, 2007. 
BRASIL. Decreto n ${ }^{\circ}$ 7.794, de 20 de agosto de 2012. Institui a Política Nacional de Agroecologia e Produção Orgânica. Diário Oficial, p. 4, 2012.

BRASIL. Instrução Normativa ${ }^{\circ}$ 17, de 18 de junho de 2014. Atualiza o regulamento técnico para os Sistemas Orgânicos de Produção, bem como as listas de substâncias e práticas permitidas. Ministério da Agricultura, Pecuária e Abastecimento. Brasília, DF, 2014

BRASIL. Instrução Normativa $n^{\circ} \quad 46$, de 6 de outubro de 2011. Estabelece o regulamento técnico para os Sistemas Orgânicos de produção, bem como as listas de substâncias e práticas permitidas. Ministério da Agricultura, Pecuária e Abastecimento, DF, 2011.

BRASIL. Lei $\mathrm{n}^{\circ} \mathbf{1 . 2 8 3}$, de 18 de dezembro de 1950 . Dispõe sobre a inspeção industrial e sanitária dos produtos de origem animal. Presidência da República, Casa Civil, Rio de Janeiro, RJ, 1950.

BRASIL. Lei ${ }^{\circ} \mathbf{1 0 . 8 3 1}$, de 23 de dezembro de 2007 . Dispõe sobre a agricultura orgânica e dá outras providências. Diário Oficial da República Federativa do Brasil, Brasília, DF, 2003.

BROOKE-TAYLOR, S. Systematic review of the gastrointestinal effects of A1 compared with A2 $\beta$ Casein. Advances in Nutrition, v. 8, n. 5, p. 739-748, 2017.

CABIDDU, A.; DELGADILHO-PUGA; C.; DECANDIA, M.; MOLLE, G. Extensive ruminant production systems and milk quality with emphasis on unsaturated fatty acids, volatile compounds, antioxidant protection degree and phenol content: review. Animals, v. 9, n. 771, p. $1-17,2019$.

DALY, J. Jamaica in the Arabica coffee global value chain. Duke Global Value Chains Center.

DUARTE-VÁZQUEZ, M.Á.; GARCÍA-UGALDE, C.; VILLEGAS-GUTIÉRREZ, L.M.; GARCÍAALMENSÁREZ, B.E.; ROSADO, J.L. Production of cow's milk free from beta-casein A1 and Its application in the manufacturing of specialized foods for early infant nutrition. Foods, v.7, n. 6, p. 50, 2017.

FACCIA, M. The flavor of dairy products from grassfed cows. Foods, v. 9, n. 1188, 2020.

FALQUETO, J.M.Z.; HOFFMANN, V.E. FARIAS, J.S. Saturação teórica em pesquisa qualitativas: relato de uma experiência de aplicação em estudo na área de administração. Revista de Ciências da Administração, v. 20, n. 52, p. 40 - 53, Dez., 2018.

FERNANDEZ-STARK, K.; BAMBER, P.; GEREFFI, G. Peru in the high quality cotton textile and apparel global value chain: opportunities for upgrading. Center on Globalization, Governance \& Competitiveness, Duke University, 51p., 2016a.

FERNANDEZ-STARK, K.; BAMBER, P.; GEREFFI, G. Peru in the table grape global value chain: opportunities for upgrading. Center on Globalization, Governance \& Competitiveness, Duke University, 52p., 2016 b.

FONTANELLA, B.J.B.; MAGDALENO JÚNIOR, R.M. Saturação teórica em pesquisas qualitativas: contribuições psicanalíticas. Psicologia em Estudo, Maringá, v. 12, n. 1, p. 63 - 71, 2012.

FONTANELLA, B.J.B.; RICAS, J.; TURATO, E.R. Amostragem por saturação em pesquisas qualitativas em saúde: contribuições teóricas. Cad. Saúde Pública, Rio de Janeiro, v. 24, n. 1, p. 17 - 27, 2008.

FOOD AND AGRICULTURE ORGANIZATION OF THE UNITED NATIONS (FAO); GLOBAL DAIRY PLATFORM INC. Climate change and the global dairy cattle sector: the role of the dairy sector in a low-carbon future. Rome, Itália, 36 p., 2019.

GEREFFI, G.; FERNANDEZ-STARK, K. Global value chain analysis: $A$ primer, $2^{\text {nd }}$ Edition. Center on globalization, governance e competitiveness, Duke University, 2016.

GEREFFI, G.; FERNANDEZ-STARK, K. Global value chain analysis: A Primer. Center on Globalization, Governance \& Competitiveness (CGGC), Durham, North Carolina, Duke University, 2011.

GEREFFI, G. What does the COVID-19 pandemic teach us about global value chains? The case of medical supplies. Journal of International Business Policy, v. 3, p. 287 - 301, 2020. Disponível em: https://link.springer.com/content/pdf/10.1057/s42214020-00062-w.pdf. Acesso em: 3 set. 2020.

GRADINARU, A.C.; PETRESCU-MAG, I.V.; OROIAN, F.C.; BALINT, C.; OLTEAN, I. Milk protein polymorphism characterization: a modern tool for sustainable conservation of endangered Romanian cattle breeds in the context of traditional breeding: review. Sustainability, v. 10, n. 2, p. 534, 2018. 
HANDCOCK, M.S.; GILE, K. Comment: on the concept of snowball sampling. Sociological Methodology, Los Angeles, v. 41, n. 1, ago., p. $367-$ 371, 2011.

JIANQIN, S.; LEIMING, X.; LU, X.; YELLAND, G.W.; NI, J.; CLARKE, A.J. Effects of milk containing only A2 beta casein versus milk containing both A1 and A2 beta casein proteins on gastrointestinal physiology, symptoms of discomfort, and cognitive behavior of people with self-reported intolerance to traditional cows' milk. Nutrition Journal, v. 15, n. 35, 2016.

LIMA, S.K.; GALIZA, M.; VALADARES, A.; ALVES, F. Produção e consumo de produtos orgânicos no mundo e no Brasil. Texto para discussão 2538, Brasília: Rio de Janeiro: Ipea, 2020.

LOWE, M.; GEREFFI, G. A value chain analysis of the US beef and dairy industries. Center on Globalization, Governance \& Competitiveness, Duke University, 2009.

MARCHI, V.; MARIA, E. Environmental upgrading and suppliers' agency in the leather global value chain. Sustainability, v. 11, n. 23, p. 6530, 2019.

MENDONÇA, M.V.; PEDROZA FILHO, M.X. Análise do cacau orgânico de São Félix do Xingu (PA) através da cadeia global de valor. Agroecossistemas, v. 11, n.1, p. 20 - 42, 2019. Disponível em: https://ainfo.cnptia.embrapa.br/digital/bitstream/item/2 08198/1/CNPASA-2019-agroecossistemas.pdf. Acesso em: 7 set. 2020.

MINISTÉRIO DA AGRICULTURA, PECUÁRIA E ABASTECIMENTO (MAPA). Em sete anos, triplica o número de produtores orgânicos cadastrados no ministério. MAPA, Brasília, 2019.

MINISTÉRIO DA AGRICULTURA, PECUÁRIA E ABASTECIMENTO (MAPA). Produtos orgânicos: o olho do consumidor. Brasília, 2009. Disponível em: https://www.gov.br/agricultura/pt-

br/assuntos/sustentabilidade/organicos/arquivos-

publicacoes-organicos/cartilha_ziraldo-1.pdf/view.

Acesso em: 2 set. 2020.

MISHRA, B.P.; MUKESH, M.; PRAKASH, B.; SODHI, M.; KAPILA, R.; KISHORE, A.; KATARIA, R.R.; JOSHI, B.K.; BHASIN, V.; RASOOL, T.J.; BUJARBARUAH, K.M. Status of milk protein, $\beta$ casein variants among Indian milch animals. Indian
Journal of animal Sciences, v.79, n. 7, p. 722-725, July, 2009.

ORGANIS \& MARKET ANALYSIS. Consumo de produtos orgânicos no Brasil: primeira pesquisa nacional sobre o consumo de orgânicos. ORGANIS \& MARKET ANALYSIS, Brasil, 2017, 57 p.

OTTE, M.J.; FELIS-ROTA, A. Dairy development's impact on poverty reduction. FAO, GDP and IFCN, Chicago, Illinois, USA. Licence: CC BY-NC-SA 3.0 IGO, 2018.

PALMAS. Lei $\mathbf{n}^{\circ} \mathbf{1 . 2 2 8}$, de 23 de outubro de 2003. Dispõe sobre as normas sanitárias para elaboração e comercialização de produtos artesanais comestíveis de origem animal e vegetal no município de Palmas e adota outas providências. Câmara Municipal de Palmas, 2003.

PEDROZA FILHO, M.X.; BARROSO, R.M.; FLORES, R.V. Diagnóstico da cadeia produtiva da piscicultura no estado de Tocantins. Embrapa Pesca e Aquicultura, Boletim de P\&D, n.5, 2015.

POLASTRINI, A.; PEDROZA FILHO, M.X.; OLIVEIRA, N. Gargalos da cadeia leiteira de Palmas TO: abordagem de cadeia global de valor. IGEPEC, Toledo, v. 24, n. 2, p. 195 -212, jul./dez. 2020.

RAHIMI, Z.; GHOLAMI, M.; RAHIMI, Z.; YARI, K. Evaluation of beta-casein locus for detection of $A 1$ and A2 alleles frequency using allele specific PCR in native cattle of Kermanshah, Iran. Biharean Biologist, Oradea, Romania, v. 9, n. 2, p. 85-87, 2015.

SISTEMA IBGE DE RECUPERAÇÃO AUTOMÁTICA (SIDRA). SIDRA 2020. 2020. Disponível em: https://sidra.ibge.gov.br/home/pms/brasil. Acesso em: 11 mar. 2020.

SILVA, A.M.; SILVA, J.C.S.; SILVA, L.K.M.; OLIVEIRA, A.R.N.; MOURA, D.M.F. Conjuntura da pecuária leiteira no Brasil: bovinocultura leiteira, cadeia produtiva, agronegócio. Nutritime Revista Eletrônica, on-line, Viçosa, v. 14, n.1, p. 4954 - 4958, 2017.

TOCANTINS. Lei $\mathbf{n}^{\circ} \mathbf{1 . 8 9 6}$, de 28 de fevereiro de 2008. Diário Oficial $n^{\circ} 2.601$ que dispõe sobre a elaboração e comercialização de produtos comestíveis artesanais de origem animal e vegetal no Estado do Tocantins. Governo do Estado do Tocantins, 2008. 
UNITED NATIONS. World urbanization prospects: the 2018 revisions. Key factors. Population division of the UN. Department of Economic and Social Affairs, population division, New York, United Nations, 2019. Disponível em: https://population.un.org/wup/Publications/Files/WUP 2018-Report.pdf. Acesso em: 9 jun, 2020.

VILELA, G.F.; MANGABEIRA, J.A.de C.; MAGALHÃES, L.A.; TOSTO, S.G. Agricultura orgânica no brasil: um estudo sobre o Cadastro Nacional de Produtores Orgânicos. Embrapa Territorial, Campinas, SP, Documentos 127, 20 p., 2019.

WILLER, H.; LERNOUD, D. The world of organic agriculture: Statistics and emerging trends 2019. FiBL \& IFOAM - Organics International, 20th ed. Switzerland: [s.n], 2019 